\title{
Encenação e Interpretação Teatral como Processo de Aprendizagem
}

A mesa temática "Encenação e Interpretação Teatral como Processo de Aprendizagem” pretende abordar as etapas artístico-pedagógicas da montagem do espetáculo de teatro Inimigos do Povo, livremente inspirada em Um Inimigo do Povo, do autor norueguês Henrik Ibsen, feita pela Trupe dos Conspiradores ${ }^{1}$, coletivo teatral formado em 2017 por professores e alunos do Curso de Licenciatura em Teatro da Universidade Federal de Rondônia (UNIR).

Tal montagem iniciou-se a partir de experiências interpretativas levadas a cabo na disciplina Laboratório de Interpretação $\mathrm{I}^{2}$. Nesta, com discentes do segundo período do referido curso, estudamos técnicas interpretativas realistas do encenador-pedagogo russo Constantin Stanislávski. Para tais experimentos escolhemos o texto Um Inimigo do Povo, de Ibsen. Paralelamente a essa disciplina, com a mesma turma de alunos, e utilizando tal peça ibsiniana, desenvolvemos o processo também na disciplina Laboratório de Improvisação Teatral II, no primeiro semestre letivo de 2017 (2017/1). A seguir, elenco algumas das técnicas interpretativas stanislavskianas utilizadas em ambas as disciplinas: Imaginação, “Se” Mágico, Circunstâncias Dadas (ou Circunstâncias Propostas), Subtexto, Entonações e Pausas, Unidades e Objetivos, Ação Física e Ação Vocal, Memória das Emoções, Tempo-ritmo no movimento, Tempo-ritmo no falar e Caracterização de personagens.

Tanto em uma quanto em outra disciplina exploramos teórica e praticamente as técnicas apontadas, tendo sempre como base para as investigações cênicas a peça de Ibsen. Contudo, algumas diferenças metodológicas ocorreram, levando-se em consideração as ementas de cada uma das matérias. Nas aulas de Interpretação I, por exemplo, seguindo-se a sequência de técnicas interpretativas anteriormente relacionadas, trabalhávamos uma hora de aquecimento (corporal e vocal); uma hora de discussão teórica a partir de textos de Stanislávski, extraídos principalmente das obras A preparação do Ator e A Construção da personagem; e duas horas de experimentações práticas. A parte prática sempre refletia a teoria discutida no dia. Vejamos, como exemplo, uma aula ministrada em 06 de abril de 2017, que teve como texto teórico o Capítulo IV (Imaginação) de A Preparação da Personagem. Nesse dia, em duplas, os alunos trabalharam com um Tema passivo (Divã de Personagens de Um Inimigo do Povo: um paciente - Dr. Stockmann, o prefeito Peter, a Sra. Stockmann, Petra,

1 Este é o site da trupe: <https://trupedosconspiradores.wordpress.com/>. Acesso em: 31 mar. de 2018.

2 No Curso de Licenciatura em Teatro da UNIR sou o professor das seguintes disciplinas obrigatórias: Laboratório de Improvisação Teatral I e II, Laboratório de Interpretação Teatral I, Linguagem da Encenação Teatral e Fundamentos da Direção Teatral. E professor das optativas Atuação com Objetos e Teatro de Formas Animadas. 
etc., - desabafando os seus problemas com um psicólogo), com um Tema Ativo (os mesmos pacientes, utilizando como texto os seus desabafos com o psicólogo, agindo em situações do cotidiano: tomar banho, cozinhar, dar aula e assim por diante) e com a Construção das Ações Anteriores das personagens: como era o Dr. Stockmann jovem, solteiro, antes de ter se formado como médico? E a Sra. Stockmann, esposa do Dr. Stockmann, como era em sua juventude? Para finalizar a aula, visando o relaxamento dos alunos-atores, propus um exercício de “Imaginação Sugestionável” que intitulei “O Ciclo da Água”. Deitados, de olhos fechados e ouvindo a música dois (Forest Reverie) do CD Tranquilit - After the Rain, de Hennie Bekker, os alunos-atores deveriam imaginar seus corpos como água em um ciclo: do nascimento no alto de uma montanha, passando pela formação de um rio caudaloso, pela evaporação, pela formação de nuvens de chuva e até a sua completa precipitação na Terra.

Já em Improvisação II, além de abordar as técnicas interpretativas de Constantin Stanislávski, trabalhei com improvisações advindas de imagens disparadoras - levadas por cada um dos discentes - constantes em duas imagens pictóricas ou fotográficas (sendo uma de um animal), uma imagem textual (a partir de Um Inimigo do Povo, de Ibsen) e de uma imagem musical. Todas as imagens disparadoras teriam que se relacionar com as personagens ibsenianas escolhidas pelos alunos-atores, bem como aproximar-se do contexto sócio-políticocultural da peça do autor norueguês. A título de amostragem, permita-me examinar a aula do dia 07 de abril de 2017, esta avaliativa, na qual os alunos-atores levaram duas imagens pictóricas ou fotográficas para improvisarmos. Começamos a aula, também de quatro horas, pelo “1- Museu de Imagens”3, que constava da exposição e explicação das imagens escolhidas por cada discente. Individualmente, tentando agir como a personagem selecionada a partir do texto de Ibsen, que por sua vez deveria tornar-se um guia museológico, cada aluno-ator precisaria responder às perguntas feitas pelos visitantes do seu "museu” acerca das suas duas imagens: "qual o por quê das escolhas dessas imagens? Como elas podem se relacionar com a sua personagem? Em termos de sentidos, o que elas representam? Qual a aproximação pode ser feita entre sua personagem e a imagem do animal selecionada?”4; dentre tantas outras questões. Lembro-me de alguns pares de imagens levados pelos discentes: uma cadelinha (representando a Sra. Stockmann obediente e submissa) e uma Chefe de Cozinha (figurando essa mesma personagem em uma ação cotidiana, enquanto dona de casa), cujo título ${ }^{5}$ era “A

3 Anotações extraídas do meu caderno de anotações e de preparativos das aulas.

4 Idem.

5 Os alunos-atores, inspirados no capítulo “Unidades e Objetivos” do livro A preparação do ator, de Constantin Stanislávski, deveriam dar um título às suas imagens disparadoras oriundas das imagens pictóricas e/ou fotográficas. Tal título deveria conter um substantivo, um verbo e um adjetivo. Todos esses títulos constam do meu caderno de professor. 
cadela Catarina continua a cozinhar”; uma piranha e uma mulher fumando um cachimbo (que seria a versão feminina do corrupto editor de jornal Hovstad), das quais uma aluna-atriz formou a frase "Joana, a piranha fumadora de cachimbo"; um gato (animal solitário) e uma fotografia de um escritório para figurar o Prefeito Peter em seu local de trabalho, cuja oração foi "O prefeito cuidando da sua imagem influente”; uma imagem de coruja (ave símbolo da sabedoria) e uma foto de um livro para traduzir características da professora Petra, a partir das quais formou-se a frase "Petra, compartilhadora de conhecimentos verdadeiros"; dentre outras tantas imagens. Após a dinâmica do museu, inspirada em jogos dramáticos de Jean-Pierre Ryngaert, passamos às improvisações. A primeira foi "2- Improvisação com Imagem A (pictórica e/ou fotográfica)”, que se deu nesta série:

A- Copiar a posição exata da imagem e movimentar-se, congelando-se, ao final, na mesma posição inicial (posição 0); B- Iniciando pela posição 0, construir uma partitura de cinco movimentos; C- Acrescentar sons e ruídos à essa partitura; DConstruir pontes sonoras e de movimentos para ligar cada movimento da partitura, objetivando criar uma sequência orgânica; E- A partir da personagem escolhida do texto Um Inimigo do Povo, construir uma pequena história ou narrativa visual e sonora. Utilizar, para tanto, "ses” mágicos, imaginação ativa, circunstâncias dadas e subtexto; F- Apresentar a história para a turma ${ }^{6}$.

Em seguida, entramos em “3- Improvisação com Imagem B (Animalesca)”. A sequência desse exercício foi a seguinte:

A- Repetir o item A da Improvisação de número 2; B- Retomar a partitura de cinco movimentos dessa improvisação dando-lhe características do animal da Imagem B; CAcrescentar sons e ruídos de animais a essa partitura; D- Fazer o item D do exercício 2 com características do animal escolhido; E e F- Idem ao item E e F do exercício 2, mas observando-se os caracteres animalescos. ${ }^{7}$

Por último, passamos ao "4- Improvisação com mescla das Imagens A e B”, cujo objetivo era tentar animalizar a figura humana e humanizar a figura animal. Podia-se repetir toda a sequência de A a F da improvisação 1 com elementos do exercício 2. E vice-versa. Nas aulas seguintes improvisamos as sequências criadas chocando-as com as Imagens Textuais e Imagens Musicais levadas pelos discentes. Isso proporcionou a eles a criação de partituras muito complexas, que variavam de 20 a 30 ações físico-vocais.

6 Conteúdo extraído do meu caderno de anotações e de preparativos das aulas.

7 Idem. 
Em termos avaliativos, ao todo e ao fim de quarenta aulas ${ }^{8}$, foram seis provas práticas coordenadas pelo professor-encenador: três em Interpretação I e três em Improvisação II. Importa mencionar novamente que os alunos dessas duas disciplinas eram praticamente os mesmos, variando de um ou dois por disciplina. Os alunos-atores que cursavam apenas uma das disciplinas participavam voluntariamente de todas as provas práticas, mas eram avaliados somente na disciplina que estavam matriculados. Analisemos, brevemente, as provas práticas de Interpretação I:

\begin{abstract}
Prova Prática I: criar uma partitura vocal, a partir do segundo capítulo (Partitura Vocal) da obra "Voz; Partitura da Ação", de Lúcia Helena Gayotto, memorizá-la e colá-la à partitura de ações físicas de sua personagem; Prova Prática II: Caracterizar sua personagem, considerando o capítulo "Para uma caracterização física", do livro $A$ Construção da Personagem, de Constantin Stanislávski, apresentando a cena 5 do Ato I e a cena 5 do Ato II do texto Um Inimigo do Povo, de Ibsen. Além da caracterização física (utilizando maquiagens, figurinos e objetos de cena), cada aluno-ator deve apresentar novas ações físicas e vocais da sua personagem, considerando-se a situação (circunstâncias dadas + emoções) e a relação com as demais personagens das cenas. Prova Prática III: apresentação pública das cenas desenvolvidas. Estas devem ter cenário, figurinos, trilha sonora e iluminação. ${ }^{9}$
\end{abstract}

Já as provas de Improvisação II foram estas: A- Prova Prática I: Improvisações dirigidas a partir de imagens musicais, nas quais cada discente deveria coordenar, enquanto professor-diretor, improvisações a partir de uma música selecionada por ele; B- Prova Prática II: apresentação coletiva da Cena I do Ato IV de Um Inimigo do Povo - Julgamento do Dr. Stockmann, que foi feita por meio de paisagem sonora (ou paisagem auditiva); C- Prova Prática III: a mesma prova prática da disciplina Interpretação I, porém, a avaliação do professor-encenador enfatizou os aspectos improvisacionais do processo de montagem. Findado o primeiro semestre letivo de 2017, a maior parte dos discentes das duas disciplinas optou por continuar com o processo de montagem de Inimigos do Povo em Interpretação II, cuja disciplina fora cedida a mim para a continuidade do processo.

No semestre seguinte (2017/2), durante a disciplina Laboratório de Interpretação II, submetemos os experimentos cênicos aos princípios interpretativos de Bertolt Brecht. Ainda nesse semestre, duas alunas da matéria Linguagem da Encenação Teatral, ingressaram no processo artístico-pedagógico: uma como atriz e outra como assistente de encenação. Para a avaliação desta última aluna, pedi a ela que dirigisse a Cena III (Alegria no Jornal) do Ato II

8 Todas as quatro disciplinas mencionadas até aqui neste resumo possuem carga horária de 80 h/a. Cada aula tem duração de 4 h/a. Logo, ao final de cada disciplina, tínhamos 20 encontros. Somando-se os dias que nos encontramos em Interpretação I e Improvisação II tem-se um total de 40 encontros.

9 Conteúdo extraído do meu caderno de anotações e de preparativos das aulas. 
de Inimigos do Povo. Outros fatores importantes desse período foi o começo dos ensaios no Teatro Guaporé (palco italiano) da Fundação Cultural do Estado de Rondônia (FUNCER), sempre nas tardes das terças-feiras, e a entrada de um preparador corporal no processo.

Em Interpretação II, os processos criativos de Inimigos do Povo começaram a se distanciar do realismo de Stanislávski e se aproximar ao Teatro Épico de Bertolt Brecht, bem como ao grotesco. Como obra teórica de referência utilizamos Estudos sobre Teatro, de Brecht. As ideias brechtianas de teatro didático, teatro político e dialética, assim como a representação épica (efeito de distanciamento, historiação dos acontecimentos, gestus, narração em primeira e em terceira pessoa e songs) deram um tom ainda mais forte de crítica político-social à nossa criação. Um exemplo do método pedagógico adotado por mim durante essa disciplina pode ser notado na aula ministrada no dia 16 de novembro de 2017:

1- Discussão dos textos "Notas sobre a peça A Mãe” e "Notas sobre A Ópera de três Vinténs”. 2- Prática: A- Trabalhar linhas, vetores e espaço; B- Grotesco: animalizaçãohumanização; C- Trabalho sobre olhos e mãos; D- Síncope; E- Dilatação corporal; FEstado de Suspensão. ${ }^{10}$

De forma semelhante às disciplinas Interpretação I e Improvisação II, as avaliações de Interpretação II também foram por meio de três provas práticas. Vejamos o conteúdo pedido para uma delas: "Utilizando o Capítulo 17 (Recursos de Distanciamento) da obra O Teatro Épico, de Anatol Rosenfeld, fazer experimentos práticos com sua personagem de Inimigos do Povo" "11. A prova final de Interpretação II constou de um ensaio aberto à comunidade acadêmica da UNIR e da comunidade em geral de Porto Velho.

No presente semestre letivo (2018/1), findadas as disciplinas de interpretação e improvisação, ademais de ainda estar ligada à matéria Fundamentos da Direção Teatral, que conta com a participação da mesma discente de Linguagem da Encenação Teatral, a montagem tornou-se um projeto de extensão (Trupe dos Conspiradores: pesquisa e prática em encenação e em atuação - $40 \mathrm{~h} / \mathrm{mês})$, que teve a entrada de novos artistas e profissionais da capital rondoniense. Além disso, foi contemplada com o Prêmio de Teatro Jango Rodrigues, na categoria montagem. Enfim, continuamos com os ensaios no período vespertino, no contraturno, portanto, haja vista o nosso curso ser matutino. Ensaiamos três vezes por semana: duas na UNIR, no recém-criado Laboratório de Criação Cênica, e uma no Teatro Guaporé da FUNCER. A previsão de estreia de Inimigos do Povo é para o dia 07 de

10 Conteúdo extraído do meu caderno de anotações e de preparativos das aulas.

11 Idem. 
julho de 2018, dentro da II Mostra de Encenações da Unir, a ocorrer no Teatro Guaporé, que será organizada pela nossa trupe e pelo Departamento de Artes/Teatro.

\section{Referências:}

BRECHT, Bertolt. Estudos sobre o teatro. Trad. Fiama Pais Brandão. 2. ed. Rio de Janeiro: Nova Fronteira, 2005.

GAYOTTO, Lúcia Helena. Voz partitura da ação. São Paulo: Summus Editorial, s.d.

IBSEN, Henrik. Um Inimigo do Povo. Trad. Pedro Mantiqueira. Porto Alegre: L\&PM, 2011.

RYNGAERT, Jean-Pierre. Jogar, representar: práticas dramáticas e formação. Trad. Cássia Raquel da Silveira. São Paulo: Cosac Naify, 2009.

ROSENFELD, Anatol. O teatro épico. 4. ed. São Paulo: Perspectiva, 2006.

STANISLAVSKI, Constantin. A Construção da Personagem. Trad. Pontes de Paula Lima. 15. ed. Rio de Janeiro: Civilização Brasileira, 2005.

A preparação do ator. Trad. Pontes de Paula Lima. 34. ed. Rio de Janeiro: Civilização Brasileira, 2016.

\section{Site consultado:}

<https://trupedosconspiradores.wordpress.com/>. Acesso em: 31 mar. de 2018. 